\title{
Organizational optimization of construction processes by virtue of robotization
}

\author{
Elena Makovetskaya ${ }^{1, *}$, Antonina Deniskina ${ }^{2}$, Egor $_{\text {Krylov }}^{3}$ and Fatima Urumova $^{4}$ \\ ${ }^{1}$ Tyumen Industrial University, Volodarskogo str., 38, Tyumen, 625000, Russia \\ ${ }^{2}$ Moscow Aviation Institute, Volokolamskoe highway, 4, Moscow, 125993, Russia \\ ${ }^{3}$ Moscow State University of Civil Engineering, 129337, 26, Yaroslavskoe Shosse, Moscow, Russia \\ ${ }^{4}$ Moscow Region State University, Radio str., 10A, 105005, Moscow, Russia
}

\begin{abstract}
The comparative analysis of two options for investment and construction projects, with partial robotization of production and traditional work organization was conducted on the criterion of time and cost minimizing the of construction. The use of two robot types was considered, a bricklayer and a plasterer robot. As a comparison result of main quantitative indicators of construction organization plan, it was found that the use of robots reduced the duration of construction, expenditures and labor costs. Lack of fatiguability, lunch breaks, smoke breaks, conversations, illnesses, as well as round-the-clock operation, the absence of malicious intents, no theft and, therefore, procedural violations, composition disorders, etc., allows to look at the introduction prospect of construction robots with optimism.
\end{abstract}

\section{Introduction}

Information analysis on the number of accidents and injuries during the construction of buildings and structures occurring in recent years led to thoughts about the causes of the disappointing trend - the number of accidents and injuries increases every year. In confirmation of this, accident rates in the Czech Republic and Russia were compared. In order to conduct the proper analysis, the number of serious injuries up to 2015 (accidents with incapacity for more than 3 days) was recalculated per 100 employees (tables 1,2). In 2016 and 2017, the number of injured in the Russian Federation is almost the same, 1949 and 1950 , respectively.

Table 1. The number of serious injuries in the construction industry of Czech Republic.

\begin{tabular}{|l|l|l|l|l|l|}
\hline & 2011 & 2012 & 2013 & 2014 & 2015 \\
\hline Workers & 393,336 & 393,560 & 374,264 & 367,929 & 360,013 \\
\hline Injured & 168 & 78 & 63 & 97 & 121 \\
\hline per 100 workers & 0.043 & 0.020 & 0.017 & 0.026 & 0.034 \\
\hline
\end{tabular}

\footnotetext{
${ }^{*}$ Corresponding author: a.copytowa@yandex.ru
} 
Table 2. The number of serious injuries in the construction industry of Russia.

\begin{tabular}{|l|l|l|l|l|l|}
\hline & 2011 & 2012 & 2013 & 2014 & 2015 \\
\hline Workers & $547,360,0$ & $564,190,0$ & $571,190,0$ & $566,410,0$ & $565,190,0$ \\
\hline Injured & 4482 & 3832 & 3310 & 2711 & 2371 \\
\hline per 100 workers & 0.082 & 0.068 & 0.058 & 0.048 & 0.042 \\
\hline
\end{tabular}

The main injury causes are:

1. operation of defective machines, mechanisms and equipment $-29 \%$;

2. poor work organization $-26 \%$;

3. traffic offense $-12 \%$;

4. violation of labor regulations and labor discipline $-8 \%$;

5. organizational shortcomings regarding the labor protection training for workers $-6 \%$;

6 . violation of processing procedure $-6 \%$;

7. Unsatisfactory exploitation and organizational drawbacks of workspace organization $-5 \%$;

8. non-use of personal protective equipment by workers $-4 \%$.

non-use of personal protective equipment by workers $-4 \%$.

Thus, the main cause of accidents, injuries and death of workers, as a rule, is unsafe behavior at the construction site. Open disregard of rules is an internal reason which depends on many factors, such as physical and moral state of the employee, his responsibility, attentiveness, etc. One way of reducing the subjectivity can be the implementation of robots and manipulators into the technological and organizational processes of construction. Therefore, the main purpose of the paper is to analyze the possibility and validity of using the robots in construction.

There are numerous studies regarding robotization, which have been carried out in Russia and abroad since the 80 s of the 20th century. The leading role among them is taken by VNIIstroydormash, Central Scientific Research Institute of Industrial Automation, Moscow State Institute of Railway Engineering, Spetszhelezobetonstroy, Munich University of Technology. The problems regarding automation and robotization of operations in construction are based on the studies of scientists, such as Frolov K.V., Popova E.P., Yurevich E.I., Makarova I.M., Kuleshov A.I., Lokoty H.A., Yushchenko A.C., Poduraeva Yu. V., Zenkevich S.A., Lokhina V.M., Burdakova S.F., et al. They made a significant contribution to the establishment and development of the theoretical robotics foundations. Significant contribution to solving the robotization problem considering construction operations was made by scientists Vilman O.A., Evdokimov V.A., Vorobyev V.A., Parshin D.Ya., Zagorodnyuk V.T., Bulgakov A.G., Maksimychev O.I., et al.

However, despite the wide range of scientific and design projects in the field of construction robotics, the automation and robotization level of construction operations in Russia remains quite low. This requires the systemization of conducted researches and developments, the implementation of complex scientific-research and developments [1-3].

There are some notable foreign firms which develop and implement robotization methods in construction, such as, "Muk" (Switzerland), "Loadall" (England), "Brokk" (Sweden), and others. "Muk" use robots for earthworks, "Loadall" use them for handling operations, and "Brokk" for the reconstruction purposes. Swedish firms "Atlas Copco" and "Brock" began to make robots for laying concrete during the road maintenance works $[4,5]$.

As a result of the analysis, the whole variety of construction manipulators and robots on the market can be divided into groups by criterions of purpose as well as technological and structural features. 
One of the main groups consists of manipulators and robots for erection works. Robotization devices of this group are characterized by a wide mobility range, carrying capacity and increased positioning accuracy. The group of manipulators and robots is used for laying and compacting concrete mixtures, robotization devices forrebar placement on site, automation tools for construction and dismantling of the formwork [6,7]. There are manipulators and robots for plastering works, facing, painting, application of insulating mastic, for the casting of monolithic floors. They are distinguished by a small carrying capacity of mechanisms, high mobility, the use of software control, and the need for sensor devices $[8,9]$.

There is handling equipment designed for backfilling and compacting the ground, for laying utility systems. This type of equipment is supplied with remote, programmed control. There are manipulators and robots for handling operations with building structures and elements, containers and packages. Such manipulators can be installed on vehicles or on powered chassis [10].

At the moment, the robot market is represented by a sufficient variety of developments which perform many types of operations during the construction and reconstruction of buildings and structures. Industrial designs can replace manual labor in dangerous and tedious works. Construction robots in Russia are mainly used for reconstruction, not for the new construction. For example, in order to preserve the unique appearance of the reconstructed building in St. Petersburg, the partial demolition technique, which includes dismantling of only the internal elements of buildings) with the help of robotics was used. Another demonstrative example of implementing robots in Russia is the reconstruction of the Sayano-Shushenskaya HPP after the accident in August 2009.

The economic feasibility of implementing robots in new construction is to be considered, as well as substantiation for reducing the time and cost of building production due to partial robotization of building production processes without lowering the quality of building products. The optimal ratio of the duration, cost and quality criteria is one of the main problems of construction. Changing one of the criteria will inevitably lead to a change in the other two, tight deadlines can cause an increase in cost, and a small budget can cause a time increase, usually the quality decreases in both cases.

Robots, robotic complexes and manipulators can be integrated in almost all stages of the construction industry, and they can be divided into 5 groups as follows, depending on their work types:

erection - this group includes manipulators and robots for mounting elements of buildings, partitions made of asbestos-cement extrusion panels and phosphogypsum panels, erecting the equipment and scaffolding;

casting - laying and compaction of the concrete mixture, methods of robotization of reinforcement works at the facility, handling equipment for mounting and dismounting of construction formwork;

finishing - this group includes manipulators, robots and robotic technology systems for painting, plastering and facing works, applying insulating mastics on roofs, as well as for casting floors;

earthworks - multifunctional handling equipment designed for making excavation pits and fillets, backfilling and compaction of ground, laying of services;

handling operations - robots which perform the loading and discharging of building structures and elements, containers and packages.

Nowadays the leadership in using the robots belongs to Korea and Japan, which also occupy the first positions in the robotics market. Japan has an advanced scientific research center in the field of construction technologies, the Building Research Institute (BRI) research center, which was founded in 1946. 
In Russia, the comparable center is the Central Research and Development Institute of Robotics and Technical Cybernetics, founded in 1968. There are now practically no developments regarding the creation of construction robots, which may be due to the lack of demand for them in the construction industry, more likely this is due to the high cost of robots and the distrust of contractors to new technologies, although the experience of foreign countries shows their long-standing and successful usage.

\section{Methods}

The research subject is an eleven-story brick building which is $13 \times 40 \mathrm{~m}$ in plan. The analytical method with the use of optimization criteria was applied for the research. The list of required works was determined at the first step of calculations, such as excavation, foundation construction, backfilling, erection of the building frame, setting of precast concrete elements, roofing, window and door assembly, electrical works of the first and second stages, first and second stages of sanitary engineering works, making underfloor mattress, painting, facing, floor finishing, landscaping, other work) and the work scope.

The timing and cost of construction using the traditional approach to the construction process were calculated. As a result of the calculations, the construction period was 176 days, labor costs included 31,048 man-hours, and cost expenses were 540,362,674 rubles.

After that, the timing and cost of construction with partial robotization of the construction process were calculated. As a result of the calculations, the construction period was 124 days, 16,352 man-hours of labor costs, and the costs were 527893646 rubles. The following robots were selected for work automation; the bricklayer robot for the construction of a brick building frame (table 3) and a robot-plasterer for finishing work (table 4).

Table 3. Technical characteristics of the bricklayer robot.

\begin{tabular}{|c|c|}
\hline Characteristic & Value \\
\hline $\begin{array}{c}\text { Performance with a solid wall without } \\
\text { openings }\end{array}$ & $73 \mathrm{~m}^{3} / 8 \mathrm{~h}$ \\
\hline $\begin{array}{c}\text { Performance with a wall containing } \\
\text { openings }\end{array}$ & $40 \mathrm{~m}^{3} / 8 \mathrm{~h}$ \\
\hline Service staff & Brick loaders: 4 people. \\
& $\begin{array}{c}\text { Mortar loaders: } 1 \text { person } \\
\text { Bricklayers: } 2 \text { people. } \\
\text { Laborers: } 3 \text { people. }\end{array}$ \\
\hline Machine size & $0.84 \times 5 \times 1.1 \mathrm{~m}$ \\
\hline
\end{tabular}

Table 4. Technical characteristics of the robot-plasterer.

\begin{tabular}{|c|c|}
\hline Characteristic & Value \\
\hline Capacity & $500-750 \mathrm{~m}^{2} / 8 \mathrm{~h}$ \\
\hline Plaster height & up to $5 \mathrm{~m}$ \\
\hline Service staff & $1-2$ people \\
\hline Average cost & 400,000 rubles \\
\hline
\end{tabular}

\section{Results}

The use of robots allowed to reduce the construction period as well as costs. The comparative data of the projects are presented in table 5 . 
Table 5. Comparative data of the projects.

\begin{tabular}{|l|c|c|}
\hline \multicolumn{1}{|c|}{ Criteria } & $\begin{array}{c}\text { The project without the use of } \\
\text { robotics }\end{array}$ & $\begin{array}{c}\text { The project with the use of } \\
\text { robotics }\end{array}$ \\
\hline Construction period, $\mathrm{d}$ & 176 & 124 \\
\hline Labor costs, man-hours & 31048 & 16352 \\
\hline Costs, rub & 540362674 & 527893646 \\
\hline
\end{tabular}

The implementation of robots led to the reduce in construction period by $30 \%$ and costs by $3 \%$. A relatively insignificant decrease in costs is due to the fact that the calculation was carried out for the case of rent without purchasing the robots. This case was considered due to the small amount of work, for which the purchase of a robot is inexpedient. So, for example, the monthly rent of a robot-plasterer is about a quarter of its total cost.

The payback period of robots was also calculated.

The productivity of four plasterers and one robot-plasterer is from 200 to $350 \mathrm{~m}^{2}$ of finished plastering per day, 4000 to $7000 \mathrm{~m}^{2}$ of finished plastering. Considering the average price of 150-300 rubles per $\mathrm{m}^{2}$ of plastering with an average wage of plasterers up to 60000 rub per month, as well as the average cost of a robot-plasterer, which is 400000 rubles, its payback period will be between one and two months. That assumes daily use of robot and the workers serving it.

The efficiency of four bricklayers, workers and a bricklayer robot is from 120 to $219 \mathrm{~m}^{3}$ of finished brickwork per day, so the productivity of the brigade with the same content per month will be from 2640 to $4818 \mathrm{~m}^{3}$ of finished brickwork. Considering the average price of 2500-3500 rubles per $\mathrm{m}^{3}$ of brickwork with an average wage of bricklayers and workers up to 60,000 rubles per month, as well as the average cost of a bricklayer robot, which is $50,000,000$ rubles, its payback period will be from 3 to 8 months. As a result, it's use is more efficient for the complex development of the territory [12-15].

The considered robots have a number of disadvantages, but this does not reduce the effectiveness of their use. Thus, for example, a plasterer robot cannot work on flight of stairs and facades, since there is no solid surface for above and below fixing. Floor height is limited to $5 \mathrm{~m}$. Robot-plasterer requires people, since the robot itself does not yet have the function of preparing the mortar, and its heavy weight makes it inconvenient to move. An example of a robot plasterer is shown in Figure 1.

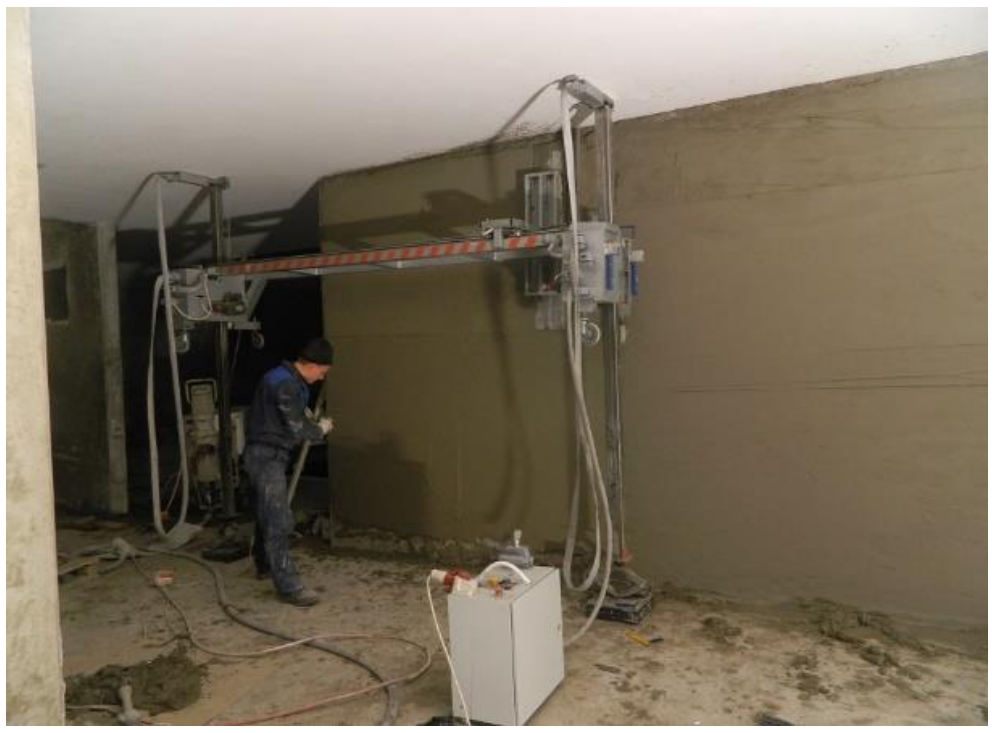

Fig. 1. Plasterer robot PlasteRUS Foreman. 
The main disadvantage of the robot bricklayer is the high cost, which makes its use profitable in projects with large amounts of work. There is also a need for human resources for loading the mortar. Thus, new results concerning the possibilities and application areas for construction robots are exposed in the paper, as well as their impact on the construction period, quality and safety of construction.

\section{Conclusions}

Analysis of the results showed that the use of robotics allowed to reduce the construction period and costs of construction by $30 \%$ and $3 \%$, respectively. A slight decrease in costs is due to the fact that the calculations were made for the case when the robotics was rented due to the small amount of construction work. Still, the use of robots brings a greater effect with large amounts of work, which is usually during complex development.

It is also highly efficient when the contractor is also the owner, not the tenant of the equipment. Taking into account some of the abovementioned limitations, at the moment it is possible and effective to integrate robotics in complex low-rise residential development of the area.

When robots are integrated into the construction process, it is advisable to use the method of continuous resource use. This method assumes labor resources (equipment and workers) to transfer to another object immediately after completing their part of the work at the previous object, which allows speeding up the construction process. This method allows the use the robotics in the most efficient way for the continuous and uniform production of construction products, while minimizing the down time.

Integrating robots in the construction process can reduce the accident and injury rate caused by a subjective factor, such as unsafe behavior, negligence and poor health, which is impossible for robots.

В результате проведенного исследования, можно сделать выводы о том, что внедрение роботов в строительстве позволит:

As a result of the conducted research, we can conclude that the integration of robots in construction will allow to:

- $\quad$ reduce the number of accidents and injuries;

- partially eliminate unskilled labor;

- reduce the cost;

- $\quad$ reduce the construction period;

- $\quad$ improve the quality of finished construction products.

The combination of unique compactness and power of robots finds its application in the most difficult conditions and hard-to-reach places on the construction site, while robotization gives a significant reduction in construction time. Coming into being of such technologies is primarily due to the desire of builders to reduce the work duration and improve its quality.

A lot of construction companies have to redo, for example, finishing work on laying floor tiles, which can be damaged due to poor-quality work performance during the first year of exploitation. It happens within the warranty coverage period and the company does it at its own expense. The work safety increases. The advantages of robots and manipulators, such as noiselessness, environmental friendliness are worth paying attention. Therefore, this technology is very appropriate in situations that are potentially dangerous to the health of workers. Lack of fatiguability, lunch breaks, smoke breaks, conversations, illnesses, as well as round-the-clock operation, the absence of malicious intents, no theft and, therefore, procedural violations, composition disorders, etc., allows to look at the introduction prospect of construction robots with optimism. 


\section{Reference}

1. K. Pykhtin, T. Simankina, V. Sharmanov, A. Kopytova, IOP Conference Series: Earth and Environmental Science, 012065 (2017)

2. Т. Воск, A. Boulgakov, D. Parshin, Proc. of the 22-th Intern. Symp. on Autom. and Robot, in Construe (ISARC-2005, Ferrara, 2005)

3. I. Valitova, T. Trofimova, T. Simankina, E. Stein, MATEC Web of Conferences, "International Science Conference SPbWOSCE-2017 "Business Technologies for Sustainable Urban Development"", 01068 (2018)

4. G. Paula, N. Kwokb, D. Liu, Automation in Construction 29, 136-147 (2013)

5. T. Schober, Bautechnik 87(2), 81-85 (2010)

6. C. Baeksuk, J. Kyoungmo, L. Myo-Taeg, Automation in Construction 32, 46-61 (2013)

7. S. Yu, J. Jang, C. Han, Automation in Construction 16-3, 255-261 (2007)

8. N. Bechthold, A. Kane, P. Michalatos, Automation in Construction 39, 161-166 (2014)

9. L.Th. Bernard, P. Richardson, Intelligent Robots and Computer Vision XXVI: Algorithms and Techniques, 72520J-11 (2009)

10. S. Yu, B. Ryu, S. Lim, Automation in Construction 18(5), 644-655 (2009)

11. Y. Yu, N.M. Kwok, Q.P. Ha, Automation in Construction 20(6), 669-676 (2011)

12. O.M. Smirnova, International Journal of Civil Engineering and Technology, 9(8), 1724-1732 (2018)

13. O.M. Smirnova, International Journal of Civil Engineering and Technology, 9(8), 1733-1740 (2018)

14. A.A. Heravi, O. Smirnova, V. Mechtcherine, RILEM Bookseries, 15, 266-274 (2018)

15. O.M. Smirnova, D.A. Potyomkin, International Journal of Civil Engineering and Technology (IJCIET). Vol. 9, Issue 7, 874-880. (2018) 